- plunged between them and the planet researchers are refining their estimates of the rings' mass, as well as that of the planet's core, says Luciano Iess, a planetary scientist at the University of Rome La Sapienza.

The rings' mass provides a way to double-check calculations of their age: the more massive the rings are, the older they might be. Preliminary analysis of data from Cassini's grand-finale orbits have given Iess and his colleagues their best estimate of mass yet. "We cannot release any value yet," Iess says, "but this is the first indication that we have that probably the rings didn't form together with Saturn." By comparing those results with estimates from Cassini's dust analyser, researchers hope to be able to settle the question of ring age once and for all.

\section{MAGNETIC MYSTERY}

Cassini's magnetometer has already made some unexpected discoveries. Saturn's axis of rotation and its magnetic axis turn out to be almost perfectly aligned, says Linda Spilker, the mission's project scientist at NASA's Jet Propulsion Laboratory (JPL) in Pasadena, California. That has puzzled researchers, because models have suggested that there needs to be at least a slight offset between the two axes for the planet to maintain a magnetic field.

The finding "suggests that we don't really understand Saturn's internal structure and how the planetary dynamo is generated yet", says Michele Dougherty, a space physicist at Imperial College London. She estimates that it will take another three to six months to crunch through the data and understand exactly what they mean.

Other potential discoveries will require researchers to put together all of Cassini's data sets from its entire 13-year study of Saturn. That includes watching the planet and its moons change over time, given that 1 year on Saturn is about 29 Earth years. "We have a whole half-season of changes on Saturn and Titan to study," says Bonnie Buratti, a planetary scientist at JPL.

The Cassini team has another year's worth of funding to tease more secrets out of the data. But as of now, there are no US missions on the books to return to Saturn - unless researchers can persuade NASA or other space agencies to go back.

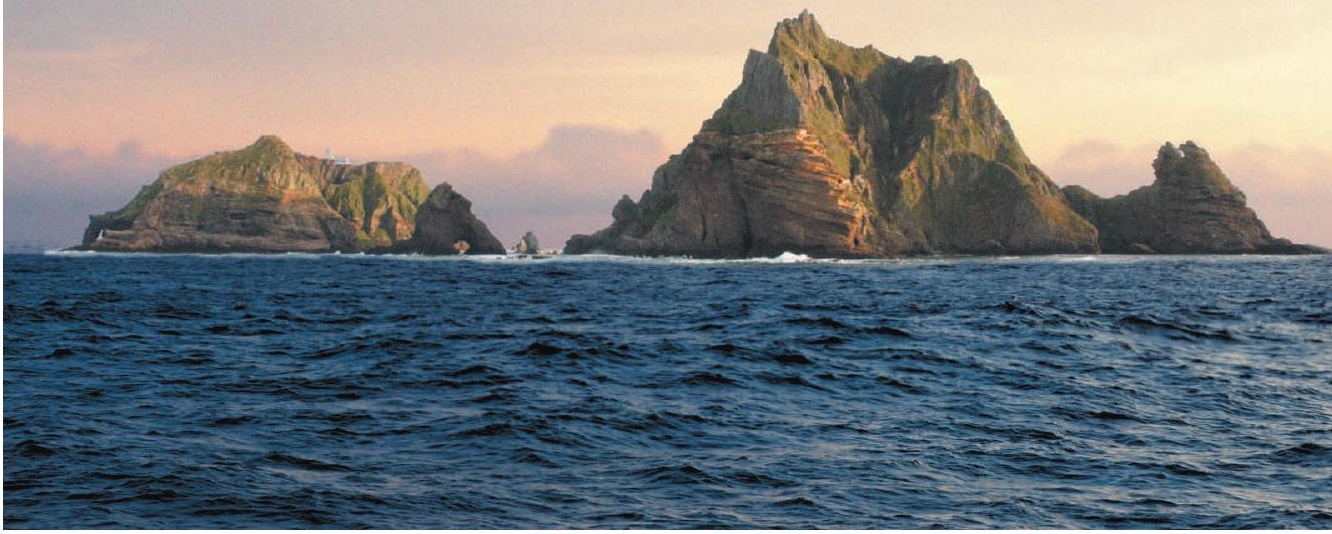

Islands between Japan and South Korea are the source of a long-running territorial dispute.

\title{
POLITICS
}

Ship name stirs up trouble

\section{Marine scientists allege that Japanese researchers have been blocked from collaboration involving a South Korean vessel.}

\section{BY MARK ZASTROW}

S outh Korea's flagship research ship Isabu seems to have sailed into a controversy with the Japanese government over its name. The incident has hindered some oceanographic research collaborations between the two countries.

The ship's name refers to a sixth-century Korean general, Kim Isabu. In South Korea, he is known for his maritime conquests, which in some historical accounts included two islets that are the subject of a decades-long territorial dispute between South Korea and Japan. Known as Dokdo in South Korea and Takeshima in Japan, the small islets are located roughly midway between the two countries, more than 200 kilometres from each mainland. The 5,900-tonne ship launched late last year and is currently cruising the Philippine $\stackrel{m}{工}$ Sea. Its name was an option in a public poll held by the ship's operator, the Korea Institute of Ocean Science and Technology in Ansan.

The Japanese government has issued no formal protest over the ship's name, but four scientists in South Korea and Japan have told Nature that researchers at Japan's national marine-research agency have been instructed not to participate in any collaborations or cruises involving Isabu. An e-mail sent in January by an official at the Japan Agency for Marine-Earth Science and Technology

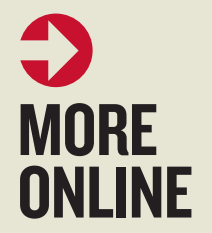

\section{TOP NEWS}

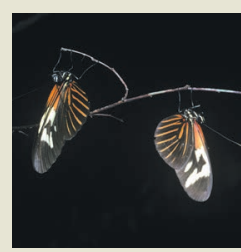

CRISPR reveals genetic master switches in butterfly wing patterns go.nature.com/ $2 w 5 z t m m$

\section{MORE NEWS}

- Seismologists stumped by mystery shock after North Korean nuclear test go.nature.com/2xfgmqe

- Researchers challenge $P$-value thresholds go.nature.com/2xccu5q

- Limiting global warming to $1.5^{\circ} \mathrm{C}$ still possible go.nature.com $/ 2 \times 80$ hau

\section{NATURE PODCAST}

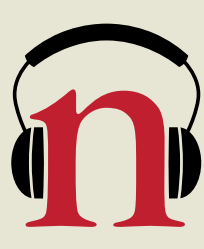

Sherlock Holmes the scientist; and investigating the nanotubes between cells nature.com/nature/ podcast 
(JAMSTEC) in Yokusuka, and seen by Nature, suggests that the order came from Japan's science ministry. The e-mail says that the ministry cancelled a proposed agreement to allow JAMSTEC researchers to collaborate on the ship.

A senior researcher at JAMSTEC, who asked to remain anonymous, says that he and other JAMSTEC researchers have been told not to use the ship or any data it obtains.

JAMSTEC's actions regarding Isabu seem to be directed from more-senior officials. An e-mail sent earlier this year from a JAMSTEC staff member to an employee of a government-supported research institute in South Korea that is involved with Isabu suggests that JAMSTEC is acting on the wishes of its supervising authority, the Japanese Ministry of Education, Culture, Sports, Science and Technology (MEXT). The e-mail said: "We have consulted MEXT on your request to add the collaboration on the research activities using your new research vessel 'ISABU', and got a negative answer from MEXT due to a non-scientific reason." The e-mail goes on to state that JAMSTEC cannot "carry out the collaboration using your new research vessel".

When contacted by Nature, the JAMSTEC staff member who sent the e-mail declined

to answer questions. JAMSTEC president Asahiko Taira told Nature that he had no knowledge of that specific e-mail, and he had not issued an order, or personally received one from the government, prohibiting the organization's involvement with Isabu. But he says cooperation with South Korea using the ship "could be very difficult" and would require permission from MEXT. “The name of Isabu is a little bit unfortunate,"

\section{"The name of Isabu is a little bit unfortunate."}

he says, but he adds that JAMSTEC will remain involved with an ongoing 16-nation collaboration to survey the region between the Indian and Pacific oceans, to which South Korea has committed Isabu. Pulling out of the collaboration over South Korea's use of the ship would "be a pretty stupid thing to do", says Taira.

MEXT's director of deep-sea research, Tatsuya Watanabe, says that the ministry had discussed the South Korean ship with JAMSTEC, but would not comment on whether the ministry had instructed JAMSTEC to avoid collaborations on the ship, or whether the ministry had an issue with the ship's name.
So far, the controversy has disrupted at least one planned research project between scientists from both countries. A university-based Japanese marine scientist, who also asked for anonymity, says that he had planned a cruise on Isabu in collaboration with JAMSTEC before the tensions arose. But the agency's researchers have since told him that JAMSTEC instruments cannot be used on Isabu. His project will go ahead without the equipment, reducing the data resolution.

Sang-Mook Lee, a marine geophysicist at Seoul National University, says that disruptions to the two countries' research collaborations will restrict the ship's scientific capability. "Had we known that the Japanese would react in such a way, I don't think Koreans would have chosen the name," he says.

But the senior JAMSTEC researcher says that the dispute is unlikely to have a major impact on Japan's marine science because the country has its own research ships and marine projects. Even so, he is upset that the ship was given such a politically-charged name: "Scientists should be politically neutral.” -

Additional reporting by Ichiko Fuyuno.

\section{Researchers unite in quest for 'standard model' of the brain}

\section{Modelled on big physics projects, the International Brain Lab will bring together some of the world's pre-eminent neuroscientists to probe a single behaviour.}

\section{BY ALISON ABBOTT}

$\mathrm{L}$ eading neuroscientists are joining forces to study the brain in much the same way that physicists team up in mega-projects to hunt for new particles.

The International Brain Lab (IBL), launched on 19 September, combines 21 of the foremost neuroscience laboratories in the United States and Europe into a giant collaboration that will develop theories of how the brain works by focusing on a single behaviour shared by all animals: foraging. The Wellcome Trust in London and the Simons Foundation in New York City have together committed more than US\$13 million over five years for the IBL.

The pilot effort is an attempt to shake up cellular neuroscience, conventionally done by individual labs studying the role of a limited number of brain circuits during simple behaviours. The 'virtual' IBL will instead ask how a mouse brain, in its entirety, generates complex behaviours in constantly changing environments that mirror natural conditions.

The project will use chips that can record the electrical signals of thousands of neurons at once. It will also use other emerging technologies, such as optogenetics toolkits that control neurons with light. "It's a new approach that will likely yield important new insights into brain and behaviour," says Tobias Bonhoeffer, a director of the Max Planck Institute for Neurobiology in Martinsried, Germany, who is also a Wellcome Trust governing-board member.

Large-scale neuroscience projects are hardly rare. In 2013, the European Commission announced the 10-year Human Brain Project, which will cost more than $€ 1$ billion ( $\$ 1.1$ billion); and in 2014, then-president Barack Obama launched the US Brain Initiative to develop neurotechnologies, with $\$ 110$ million of funding that year. The
Allen Institute for Brain Science in Seattle, Washington, has been creating comprehensive maps of brain anatomy and neural circuitry since 2003. Japan, China, Canada and other countries also have, or are planning, their own big neuroscience initiatives.

But none operates quite like the IBL, which will be governed in a similar way to large-scale physics projects such as ATLAS and CMS, at Europe's particle-physics lab CERN. The two collaborations, at CERN's Large Hadron Collider near Geneva, Switzerland, brought together experimentalists and theoreticians from hundreds of labs worldwide to test the predictions of particle physics' standard model.

Like the massive CERN teams, the IBL has created a flat hierarchy and a collaborative decision-making process with near-daily web meetings. Instead of acting only when group consensus is reached, teams will make decisions by simple consent. "No one will be 